\title{
Verwaltungsrecht in der Klausur - Die Fälle
}

Zusätzlich zum Lehrbuch ist ein aus 16 großen Fällen bestehendes Fallrepetitorium im Carl Grossmann Verlag erschienen. Anhand der Fälle können die Lehrbuchsausführungen in der Klausurpraxis nachvollzogen und das KlausurenLösen geübt werden. Das Fallrepetitorium ist zudem online unter der CreativeCommons-Lizenz BY-SA 4.0 auf wikibooks.org erschienen und kann unter https://de.wikibooks.org/wiki/Verwaltungsrecht_in_der_Klausur bearbeitet und heruntergeladen werden.

Folgende Fälle werden behandelt:

Fall 1: Anfechtungsklage bei einer Ordnungsverfügung nach der polizeilichen Generalklausel

Fall 2: Anfechtungsklage bei Nebenbestimmungen

Fall 3: Drittanfechtungsklage gegen eine Baugenehmigung

Fall 4: Verpflichtungsklage auf Erteilung einer Baugenehmigung

Fall 5: Verpflichtungsklage auf polizeiliches Einschreiten wegen Schmähkritik

Fall 6: Fortsetzungsfeststellungsklage gegen Aufenthaltsverbot für Fußballfans

Fall 7: Fortsetzungsfeststellungsklage gegen die Untersagung eines politischen Straßentheaters

Fall 8: Fortsetzungsfeststellungsklage auf Feststellung des Bestehens eines $\mathrm{Zu}$ lassungsanspruchs einer Partei zu einer kommunalen Einrichtung

Fall 9: Leistungsklage zur Geltendmachung eines Anspruchs aus öffentlichrechtlichem Vertrag

Fall 10: Vorbeugende Unterlassungsklage bei staatlichem Informationshandeln

Fall 11: Feststellungsklage bei staatlicher Warnung im Internet vor einer Versammlung

Fall 12: Nichtigkeitsfeststellungsklage bei fehlerhafter Gaststättenerlaubnis

Fall 13: Verwaltungsgerichtliche Normenkontrolle und Kommunalverfassungsstreit

Fall 14: Antrag nach $\S 80 \mathrm{~V}$ VwGO bei einer Versammlung unter Auflagen

Fall 15: Antrag nach $\S 123$ VwGO auf Zulassung zu einer Kindertagesstätte

Fall 16: Staatshaftung für unzureichende Badeaufsicht 
